\title{
Dental attitudes, knowledge, and health practices of parents of children with congenital heart disease
}

\author{
C P Saunders, G J Roberts
}

\begin{abstract}
A total of 60 children with severe congenital cardiac disease from the Great Ormond Street Hospital for Children and Guy's Hospital children's department were matched for age, gender, social class, and ethnic origin with 60 healthy children from the trauma clinic of the Department of Orthodontics and Paediatric Dentistry at Guy's Dental Hospital, London. The parents' attitude, knowledge, and dental health practices were assessed by questionnaire.

The cardiac group had significantly poorer dental health practices than the healthy group. Of the cardiac children $18 \%$ had never visited the dentist compared with only $3 \%$ for the healthy group. It is difficult to assess the importance of this in terms of a serious health hazard. Current practice of cardiac physicians is to recommend that children with heart disease seek out and attend a dentist, the advice usually being accompanied by the presentation of a 'heart card' detailing antibiotic prophylaxis regimens if extractions are required. The data presented here shows that this strategy has failed. (Arch Dis Child 1997;76:539-540)
\end{abstract}

Keywords: dental health; gingivitis; cardiac disease

Dental care of the chronically sick child is neglected. A preoccupation with the principal medical condition often results in neglect of other facets of the child's total health. ${ }^{1}$ Children who have a medical disability in the dental situation can be defined as those whose medical condition is such that their general health is put further at risk if they suffer dental disease. Because of this risk to health, or even to life, their dental care is of vital importance. ${ }^{2}$ This group of children should be given the highest priority for comprehensive, preventive dental care from as early an age as possible. ${ }^{3}$ Cardiovascular disease in children complicates dental care by making them more susceptible to infective endocarditis, increases the risks associated with general anaesthesia, and for those children taking warfarin there is the risk of prolonged bleeding. ${ }^{4}$ About one baby in a hundred is born with a cardiac defect. ${ }^{5}$

Health education attempts to change behaviour by altering an individual's knowledge, attitudes, and beliefs about health matters. Perception of vulnerability to illness and disease is a central health belief. Among the motives prompting people to seek preventive dental care are a belief that one is susceptible to dental disease, a belief that dental problems are serious, and a belief that dental treatment is beneficial. Those who believe themselves to be highly susceptible make more preventive dental visits. $^{6}$

Higher vulnerability of children towards both general health and dental health problems has been shown to be associated with preventive dental visits. ${ }^{7} \mathrm{~A}$ higher likelihood of seeking care has been found to be associated with dental knowledge. ${ }^{8}$ There is evidence to suggest that large sections of the population in the UK are unaware of their need for oral health care. In the 1988 adult dental health survey $16 \%$ of people who thought they had no decay were recorded as having six or more teeth involved with decay. ${ }^{9}$

The purpose of this study was to investigate the dental knowledge, attitudes, and dental health practices of families of children with congenital heart disease.

\section{Methods}

Children aged 2 to 16 years with severe congenital cardiac disease attending the Great Ormond Street Hospital for Children or Guy's Hospital formed the cardiac group. The healthy group comprised siblings or some other children attending for routine recall at the trauma clinic of the children's department of Guy's Dental Hospital. Each patient in the study group was matched by age, gender, ethnic origin, and social class.

The children had a dental examination which formed part of another concurrent study. ${ }^{10}$ At the same time as the dental examination the parent completed a questionnaire to enable assessment of parental knowledge and current practice of dental health procedures. This questionnaire comprised 65 questions designed to identify the attitudes, knowledge, and dental health practices of the parents of children by exploring such issues as the parents' opinion on the seriousness of different health problems of both a general and a dental nature, the importance of different dietary practices to dental caries and gingivitis, and the dental health practices of the parent and child. Only the major differences are reported here. The full questionnaire can be obtained from the authors.

\section{Results}

The two groups of children were evenly matched for age, gender, ethnicity, and social class; 48 children with cardiac disease were 
Table 1 Dental attitudes, knowledge, and health practices

\begin{tabular}{llllll}
\hline & $\begin{array}{l}\text { Healthy } \\
\text { children } \\
\text { Problem }\end{array}$ & $\begin{array}{l}\text { Children with } \\
\text { cardiac disease } \\
(\%=y e s)\end{array}$ & $\chi^{2}$ & p Value \\
\hline $\begin{array}{llll}\text { Do you think diet will affect dental decay? } \\
\text { Do you think that toothbrushing will affect }\end{array}$ & 95 & 70 & 12.98 & $<0.0001$ \\
$\quad$ dental decay? & 72 & 47 & 2.29 & $<0.005$ \\
$\begin{array}{l}\text { Does brushing help keep gums healthy? } \\
\text { Does fluoride stop decay? }\end{array}$ & 97 & 92 & 0.2 & $<0.24 \mathrm{NS}$ \\
$\begin{array}{l}\text { Should children with congenital heart } \\
\quad \text { disease have fluoride tablets? }\end{array}$ & 85 & 75 & 0.89 & $<0.35 \mathrm{NS}$ \\
$\begin{array}{l}\text { Do fissure sealants stop decay? } \\
\text { Has your child visited the dentist? }\end{array}$ & 92 & 70 & 6.14 & $<0.01$ \\
$\begin{array}{l}\text { Does your child brush their teeth twice a } \\
\text { day? }\end{array}$ & 97 & 43 & 4.48 & $<0.03$ \\
& 73 & 55 & 7.35 & $<0.004$ \\
\hline
\end{tabular}

from Great Ormond Street and 12 from Guy's Hospital. The matching of patients by age was extremely close: healthy children were mean (SD) 8.9 (3.9) years $(n=60)$ and those with cardiac disease $8.8(4.0)$ years $(n=60)$. The parent's attitudes and beliefs towards dental health were analysed using the $\chi^{2}$ test (table 1 ).

PERCEPTION OF SEVERITY OF HEALTH PROBLEMS The parents of the cardiac children were more aware of other health problems that could be serious for their child. They were aware that contracting influenza, having a broken arm, or an infection was a serious problem for their child. Both groups thought that congenital heart disease was a serious problem. Parents of cardiac children were less aware that bleeding gums was potentially a serious problem for their child. Only half were aware that having a tooth extracted could be a serious problem for their child.

KNOWLEDGE OF DENTAL HEALTH PRACTICES

The parents of the cardiac children were less knowledgeable about the effect of diet and toothbrushing on dental decay and fewer knew that fluoride could stop decay. This was reflected in the response to who should have fluoride tablets. More of the healthy parents thought that children with a cardiac defect should take fluoride tablets than parents of the cardiac children themselves.

\section{DENTAL HEALTH PRACTICES}

More healthy children regularly brushed their teeth twice a day, whereas some of the children with cardiac disorders never or hardly ever brushed twice a day (21\%). More of the healthy parents considered that toothbrushing affected dental decay. More healthy parents and healthy children had been to the dentist. Eleven out of $60(18 \%)$ children with cardiac disease had never been to the dentist. The healthy children had more treatment than the study children at their last dental appointment. The children with cardiac disease had mainly had a check up and none had a tooth extracted. The healthy children had experienced a wide range of dental treatment: nine had an extraction.

\section{Discussion}

The parents of children with congenital heart disease were generally more aware of the potential harm to the children of debilitating illnesses such as influenza, trauma, or a systemic infection. However of specific concern is that only just over half the parents of the children with cardiac disease thought that bleeding gums were potentially harmful to children with congenital heart disease.

The knowledge of dental health practices was good among both groups, but not universally practised, especially among children with cardiac disease. In particular it was disappointing that a large number of children with cardiac disease brushed their teeth only once or no times each day. This may be because the parents and children were unaware that bleeding gums are potentially harmful and that if gingivae bleed on brushing, it is necessary to brush more to encourage resolution of the gingival inflammation. A further cause for concern is the number of parents who did not use fluoride tablets and did not even know if fluoride tablets were of any benefit.

The most disappointing and potentially the most injurious was the fact that some $18 \%$ of the children with congenital heart disease had never visited a dentist. As a consequence these patients had not received the benefit of individual preventive dental advice and, where appropriate, dental treatment. It is difficult to assess the importance of this in terms of a serious health hazard. Current practice of cardiac physicians is to recommend that children with heart disease seek out and attend a dentist, the advice usually being accompanied by the presentation of a 'heart card' detailing prophylaxis regimens if extractions are required. These present data show that this strategy has failed. Parents need more active encouragement to ensure that their children receive adequate preventive advice about dental health and the availability of dental treatment. Why do cardiologists not ensure a full health service for these children by referring them to a community dental service which could provide both preventive and restorative care?

We wish to thank Brenda Fox, Director of Hillcare Dental Services, Harrow and Hillingdon NHS Trust, for her help and financial support during the two years of the study. We are grateful to the staff of the Cardiology Department, the Great Ormond Street Hospital for Children and the Department of Paediatrics, Guy's Hospital for considerable help during the course of this study.

1 Roberts GJ, Roberts IF. Dental disease in chronically sick children. fournal of Dentistry for Children 1981;48:346-51. 2 Hobson P. The treatment of medically handicapped children. Int Dent f 1980;30:6-13.

3 Court SD. Report of The Committee on Child Health. Fit for the future. London: HMSO, 1976.

4 Moore RS, Hobsen P. A classification of medically handicapping conditions and the health risks they present in the dental care of children. 1. Cardiovascular, haematoogical respiratory disorders. Fournal of Paediatric Dentistry 1989;2:73-8.

5 Jordan SC. Dental treatment of children with heart disease. Proceedings of the British Society of Paediatric Dentistry 1979; 9:13- 7 .

6 Kegeles SS. Some motives for seeking preventive dental care. $\mathcal{F}$ Am Dent Assoc 1963;67:110-8.

7 Wright FA. Children's perception of vulnerability to illness. Wright FA. Children's perception of vulnerability
Community Dent Oral Epidemiol 1982;10:29-32.

8 Tash RH, O'Shea MM, Cohen K. Testing a preventivesymptomatic theory of dental health behaviour. Am f Public Health 1969;59:514-21.

9 Todd JE, Lader DE. Adult dental health 1988. London: HMSO, 1991

10 Franco E, Saunders CP, Roberts GJ, Suwanprasit A. Dental disease, caries related microflora and salivary IgA of children with severe congenital cardiac disease. Pediatr Dent 1996;18:228-35. 